\title{
SOPESAMENTO ENTRE O PRINCÍPIO DA PUBLICIDADE E O DIREITO À PRIVACIDADE NA SOCIEDADE INFORMACIONAL: UMA CRÍTICA HERMENÊUTICA À APLICAÇÃO DA LEI DE COLISÃO DE ALEXY NO BRASIL
}

\author{
BALANCING THE PRINCIPLE OF PUBLICITY AND THE RIGHT TO PRIVACY IN THE \\ INFORMATIONAL SOCIETY: A HERMENEUTICAL CRITIQUE TO THE APPLICATION \\ OF ALEXY'S LAW OF COLLISION IN BRAZIL
}

Eduardo Rocha Dias

\author{
Doutor em Direito pela Universidade de Lisboa. Mestre em Direito pela Universidade \\ Federal do Ceará. Professor do Programa de Pós-Graduação em Direito da Universidade \\ de Fortaleza. Procurador Federal. E-mail: eduardordias@ hotmail.com \\ Gabriela Vasconcelos Lima \\ Mestranda em Direito Constitucional da Universidade de Fortaleza. \\ E-mail: gvasconceloslima@gmail.com
}

Recebido em: 19/04/2016

Aprovado em: 08/08/2016

Doi: $10.5585 /$ rdb.v16i7.375

\begin{abstract}
RESUMO: A questão hermenêutica da colisão entre o princípio da publicidade administrativa e do direito fundamental à privacidade ganha novos contornos na Sociedade Informacional, na qual se propõe a reformulação do antigo problema da violação da liberdade individual justificada pela supremacia do interesse público, operada pela difusão do uso das novas tecnologias da informação. Questiona-se quais os limites da privacidade e quais os limites da publicidade dos atos da administração. Qual o procedimento para encontrar esses limites? E, ainda, é possível garantir a realização de ambos? Em que medida? Neste contexto, estuda-se a colisão entre o direito fundamental à privacidade e o princípio da publicidade da Administração Pública, ambos resguardados pela Constituição Federal de 1988. A crítica à aplicação da lei de colisão é ilustrada pela Suspensão de Segurança no 3.902, julgada em 2011 pelo Supremo Tribunal Federal (STF) e reiterada pelo mesmo Tribunal no acórdão do Recurso Extraordinário com Agravo no 652.777, julgado em abril de 2015. Como metodologia, utiliza-se estudo descritivo-analítico, através de pesquisa bibliográfica, legislativa e documental, adotando-se como marco teórico a Teoria dos Direitos Fundamentais de Alexy (2008). Por fim, sugere-se o reconhecimento do direito à autodeterminação informativa como uma nova faceta do direito à privacidade e possível solução ao impasse do sopesamento. Conclui-se que a solução proposta respeita na maior medida possível os princípios em colisão, limitando-os somente onde necessário, como fruto de um sopesamento responsável e racional.
\end{abstract}

Palavras-chave: Lei de Colisão. Direito Fundamental à Privacidade. Princípio da Publicidade. Hermenêutica Constitucional. Direito à Autodeterminação Informativa. 


\begin{abstract}
The hermeneutical question of the collision between the principle of administrative transparency and disclosure of information and the fundamental right to privacy is renewed in the context of Informational Society, which proposes a redesign of the old problem of the violation of individual freedoms justified by the supremacy of public interest, operated by the widespread use the new information technologies. This paper questions what are the limits of privacy and what are the limits of government disclosure of information. What is the procedure to find those limits? And yet, can one ensure the realization of both? To what extent? In this context, it studies the collision between the fundamental right to privacy and the principle of transparency in public administration, both guarded by the 1988 Federal Constitution. The critique to the application of collision law is illustrated by the Suspension of Writ of Mandamus No. 3902, judged in 2011 by the brazilian Supreme Court and confirmed by the same Court in April 2015. The methodology used is descriptive-analytic, through literature, legislative and documentary research, adopting the theoretical basis of Alexy's Theory of Fundamental Rights. Finally, it is suggested that the recognition of the right to informational self-determination is a possible solution to the problem of balancing. It is concluded that the proposed solution respects to the greatest extent possible the principles in collision, limiting them only where needed, as the result of a responsible and rational balancing.
\end{abstract}

Keywords: Collision Law. Fundamental Right to Privacy. Principle of Transparency and Disclosure of Information. Constitutional Hermeneutics. Right to Informational SelfDetermination.

SUMÁRIO: Introdução; 1. Direito Fundamental à Privacidade; 2. Transparência, Publicidade e Direito Fundamental de Acesso à Informação; 3. Análise Hermenêutica da Colisão entre o Princípio da Publicidade e o Direito à Privacidade sob o Enfoque da Teoria dos Direitos Fundamentais de Alexy; 4. Direito à Autodeterminação Informativa como Solução à Colisão entre o Princípio da Publicidade e o Direito à Privacidade; Conclusão; Referências.

\title{
INTRODUÇÃO
}

A questão tradicional da privacidade já foi clara e facilmente discernível: o governo, enquanto agente de controle social, não poderia invadir a esfera privada (entendida como propriedade, seja ela uma casa, quarto, escritório, anotações, etc.) de um indivíduo sem o devido instrumento legal outorgado quando houvessem suspeitas fundamentadas.

$\mathrm{Na}$ sociedade informacional, no entanto, este paradigma mudou. $\mathrm{O}$ desaparecimento de barreiras físicas que antes protegiam a esfera íntima, a "bolha" que determinava o que era privado e o que era público, levanta uma série de novos obstáculos para a proteção da individualidade. A privacidade de um indivíduo se realiza em esferas tanto atuais quanto virtuais (LÉVY, 1999). Desta feita, os limites antes claros e palpáveis da transparência e fiscalização esmaeceram e busca-se reencontrá-los e reafirmá-los.

Propõe-se, dessa forma, a reformulação do antigo problema hermenêutico da violação da liberdade individual justificada pela supremacia do interesse público, operada pela difusão do uso das novas tecnologias da informação. Questiona-se, assim, quais os limites da privacidade e quais os limites da publicidade dos atos da administração. Qual o procedimento para encontrar esses limites? E, ainda, é possível garantir a realização de ambos? Em que medida?

Neste contexto, o presente ensaio tem como objetivo apresentar uma discussão acerca da colisão entre o direito fundamental à privacidade e o princípio da publicidade da Administração Pública, ambos resguardados pela Constituição Federal de 1988, ilustrada pela Suspensão de 
Segurança $n^{\text {o }}$ 3.902, julgada em 2011 pelo Supremo Tribunal Federal (STF), em que se pediu a suspensão da divulgação nominal da remuneração dos servidores públicos do município de São Paulo.

Para concretizar a pesquisa proposta, no forma de artigo científico, utilizou-se como metodologia um estudo descritivo-analítico, através de pesquisa bibliográfica, legislativa e documental, adotando-se como marco teórico a Teoria dos Direitos Fundamentais de Alexy (2008).

O ensaio se divide em quatro seções distintas, nas quais se analisam, em um primeiro momento, o direito fundamental à privacidade, sua proteção jurídica e os riscos decorrentes da sociedade informacional; em seguida, o princípio da publicidade administrativa, seus desdobramentos, as possibilidades conferidas pela utilização das novas tecnologias e o contexto da ciberdemocracia e do e-government.

No penúltimo tópico, aborda-se o cerne da problemática por meio da análise da decisão do STF em sede de Suspensão de Segurança, onde se analisou a lei de colisão de Alexy (2008) e esboçaram-se algumas críticas à aplicação desta lei no ordenamento jurídico pátrio. Por fim, sugere-se o reconhecimento do direito à autodeterminação informativa como nova faceta do direito à privacidade e como possível solução ao impasse do sopesamento.

Conclui-se, portanto, que a solução proposta respeita na maior medida possível os princípios em colisão, limitando-os somente onde necessário, como fruto de um sopesamento responsável, racional, onde se consideram todas as variáveis das normas colidentes e se garante tanto a realização do interesse público quanto a proteção da individualidade.

\section{DIREITO FUNDAMENTAL À PRIVACIDADE}

A realidade em que a pessoa está inserida na contemporaneidade foi descrita por Bauman (2011) como "líquida", pois como todos os líquidos ela é mutável, está em constante transformação, não conserva a mesma forma por muito tempo. Nesse contexto, a internet surge como uma "auto estrada da informação" (BAUMAN, 2011), realizadora de profundas modificações nas relações sociais, alterando, inclusive, a forma como o indivíduo e o Estado se relacionam.

Lévy (1999, p. 28) lista uma série de consequências da proliferação e larga utilização das redes digitais interativas, tais como o isolamento e sobrecarga cognitiva, causados pelo estresse da comunicação incessante e pelo trabalho diante de telas de computador; o domínio e controle quase monopolista de algumas potências econômicas sobre funções importantes da rede; e a exploração, como no caso de teletrabalho vigiado.

As consequências citadas por Lévy (1999) afetam diretamente a forma como a privacidade e a intimidade são vistas e os limites sobre o controle que as instituições públicas e privadas podem exercer sobre os dados pessoais divulgados na rede mundial de computadores.

Estas discussões levantadas pela difusão da internet não são inéditas. Ao contrário, elas já se apresentavam, porém de forma esmaecida, com a difusão de tecnologias anteriores, que provocavam efeitos semelhantes ao da internet e que, hoje, frente à revolução informacional, parecem pálidos. Dessa forma, o telégrafo e o telefone, enquanto tecnologias de comunicação bidirecional, assim como a televisão e o rádio, em outra perspectiva, contribuíram de maneira decisiva para formar a consciência do encurtamento e, mesmo, do desaparecimento de distâncias e, consequentemente, do aumento de interação e do surgimento de questões relacionadas ao direito e/ou violação de privacidade (CELLA; ROSA, 2013).

Solove (2006) aponta a dificuldade encontrada para se conceituar "privacidade", pela subjetividade intrínseca ao instituto. $\mathrm{O}$ autor percebe ainda a falha doutrinária em traduzir as percepções subjetivas acerca da privacidade em um enunciado racional e articulado que revele as razões pelas quais sua violação é prejudicial ao indivíduo. O autor (2002) acredita, ainda, que

Revista de Direito Brasileira | São Paulo, SP | v. 16 | n. 7 | p. 05 - 20 | Jan./Abr. 2017 
para resolver os problemas referentes à privacidade, faz-se necessário desenvolver uma abordagem para sua definição, que guie a criação legislativa acerca do tema.

Apesar de se reconhecer a importância da proteção da privacidade para a efetivação da liberdade, democracia, bem estar social e bem estar individual e a necessidade desta proteção mesmo quando em colisão com outros direitos - como será tratado mais a frente neste trabalho -, ainda há dificuldade na articulação de um conceito formal, o que obsta a efetivação de leis de proteção à privacidade (SOLOVE, 2002).

Em 1890, os autores Samuel Warren e Louis Bandeis inauguram uma doutrina acerca da privacidade ao publicar o artigo intitulado "Right to Privacy" na Harvard Law Review, onde defendem que se deve tratar de forma autônoma os aspectos da personalidade humana que não se podem proteger por meio da invocação da violação de um direito de propriedade privada, da confidencialidade, da confiança, da honra ou de qualquer outro tipo de obrigação contratual. Os autores designaram esta nova faceta da personalidade de "right to beleftalone", digna de proteção frente aos riscos inerentes à larga difusão de informações que, àquela época já assustava a sociedade civil.

Rodotà (2008, p. 26) traça uma linha histórica do conceito de privacidade, remontando à desagregação da sociedade feudal, na qual poucos indivíduos que, "por necessidade ou opção viviam distantes da comunidade", possuíam o privilégio do isolamento e da privacidade, justificado pela rede de relações que conectava todos os estratos sociais. $\mathrm{O}$ autor explica que a classe burguesa, com sua ascensão sócio-econômica pós-Revolução Industrial, passa a gozar do mesmo privilégio. Neste tópico, Rodotà (2008, p. 27) afirma: "A realização das condições materiais para a satisfação da necessidade de intimidade surge como um momento de um processo mais complexo, através do qual a burguesia reconhece a própria identidade no interior do corpo social". Sendo assim, no período analisado, a privacidade não se apresenta como um direito difuso, mas como um privilégio de um segmento social que apresenta contexto sócioeconômico específico.

A privacidade passa a ser vista como um direito comum à coletividade no momento em que se configura a necessidade de reação contra modelos autocráticos e autoritários de governo e contra políticas discriminatórias (RODOTÀ, 2008). Assim, a privacidade quebra sua identificação com as classes burguesas e se transforma num instrumento de promoção da igualdade. Apesar de persistirem as diferenças sociais, todos os cidadãos gozam do mesmo direito à privacidade.

No ordenamento jurídico brasileiro, o direito à privacidade é constitucionalmente protegido pelo artigo $5^{\circ}$, inciso $\mathrm{X}$, que dispõe: "são invioláveis a intimidade, a vida privada, a honra e a imagem das pessoas, assegurado o direito à indenização pelo dano material ou moral decorrente de sua violação" (BRASIL, 1988). Esta proteção confere o status de direito fundamental à privacidade, sendo classificado, mais especificamente, como de primeira geração por ser um direito de defesa garantido individualmente a todo cidadão, face ao Estado e também a outros particulares.

O dispositivo constitucional transcrito comprova a análise feita por Solove (2006) acerca da dificuldade e falha na conceituação do instituto da privacidade, uma vez que cita-se apenas os termos "intimidade" e "vida privada" sem defini-los, o que pode originar interpretações contraditórias.

A proteção jurídica da privacidade também foi efetivada em âmbito internacional pela Convenção Americana de Direitos Humanos (CADH). O artigo desta Convenção é semelhante ao artigo $5^{\circ}$, inciso X, da Constituição Federal de 1988. Em seu artigo 11, a Convenção traz a previsão da proteção da honra e da dignidade, desdobrando-a em três incisos, sendo o segundo referente à privacidade: "Ninguém pode ser objeto de ingerências arbitrárias ou abusivas em sua vida privada, em sua família, em seu domicílio ou em sua correspondência, nem de ofensas ilegais à sua honra ou reputação". A redação do dispositivo é idêntica às redações já utilizadas 
anteriormente pela Organização das Nações Unidas nos artigos 12 da Declaração Universal dos Direitos do Homem, de 1948 e 17 do Pacto Internacional dos Direitos Civis e Políticos, de 1966. A análise feita ao dispositivo constitucional se estende a estes.

Lessig (2006) descreve a questão da privacidade na sociedade informacional como de uma "ambiguidade latente". Enquanto se facilita o controle, o que, consequentemente, deveria melhorar a segurança pública, a transparência e a eficiência estatal, ignora-se a individualidade e a intimidade do cidadão, vulnerável às buscas inadvertidas ou à divulgação de dados, tais como a remuneração (no caso, por exemplo, dos servidores públicos nos Portais da Transparência).

Pode-se destacar duas formas de coleta de dados em rede: a busca e a vigilância. Entende-se por "vigilância" a configuração de alertas em computadores de órgãos governamentais com a finalidade de coletar dados que atendam a um formato determinado. A exemplo do que se denomina de vigilância aqui, pode-se mencionar a possibilidade de um alerta ser configurado para cada vez que um e-mail que contenha a palavra "al-Qaeda" seja enviado (LESSIG, 2006). Neste exemplo, a vigilância se apresenta como uma alternativa vantajosa, pois a privacidade entra em colisão com a segurança nacional. Entretanto, da mesma forma que os computadores deste órgão governamental foram configurados para buscar pessoas falando sobre a al-Qaeda, eles poderiam ter sido configurados para buscar por e-mails elogiando determinada personalidade política. Este tipo de invasão é latente e passiva, pois só se alerta sobre aquilo que é pedido e o cidadão nem tem conhecimento, nem autorizou este alerta.

Em outro contexto, a quebra da privacidade na internet pode ser efetivada através da busca dentro de bancos de dados. Lessig (2006) explica que as informações disponibilizadas nos sítios virtuais visitados são agrupadas e mantidas em grandes bancos de dados que podem servir como meio de dirigir publicidade a um público alvo específico ou podem ser vasculhadas pelo Estado para obtenção de informações relevantes.

Entende-se, no entanto, que ao fornecer informações a um sítio de confiança, há uma expectativa de confidencialidade. Logo, estes dados não poderiam ser utilizados para fins que não os expressamente autorizados pelo usuário. No entanto, uma vez na rede, não se consegue mais controlar ou fiscalizar o caminho que esses dados percorrem.

Conforme já descrito, a questão da privacidade na internet se torna mais sutil e controversa quando em colisão com princípios de interesse público, como a transparência administrativa, o direito de acesso à informação ou a segurança nacional.Rodotà (2008, p. 42) expressa esse pensamento, ao afirmar:

As dificuldades em especificar estes princípios não derivam somente do fato de que se trata de regular uma realidade em contínua transformação. Nascem ainda da necessidade de levar em conta uma multiplicidade de exigências, interesses, valores, frequentemente em conflito entre si. Também isto é efeito das novas tecnologias, de sua penetração nas mais diversas atividades, do fato de que influenciam transversalmente os mais diversos setores. Os pares opostos, assim, multiplicam-se: autoritarismo/democracia, centralização/ descentralização, regulamentação/ desregulamentação, transparência/ intimidade, decisão/ participação... E seria possível continuar, sublinhando talvez que em cada um desses pares não se renovem somente debates tradicionais, mas se assista a uma transformação 'tecnológica' dos próprios termos das contraposições. Atualmente esse é o pano de fundo sobre o qual se projetam as políticas de proteção de dados.

Rodotà (2008), a exemplo de Lessig (2006), confere às novas tecnologias, coincidentemente a mesma caracterização que Goyard-Fabre (2003) confere à democracia: a do deus bifronte, Janos. Ele percebe que, ao mesmo tempo que as novas tecnologias possibilitam 
uma transformação positiva na forma como a sociedade se relaciona com o Estado, elas carregam consigo riscos.

Pensando em solucionar a ambiguidade inerente às novas tecnologias, quando se trata da privacidade, alguns países preveem o reconhecimento do direito à autodeterminação informativa e alguns desdobramentos deste, segundo o qual o indivíduo mantém o controle sobre o acesso de seus dados pessoais por terceiros. Assim, ele tem também o poder de determinar a retificação e atualização de dados, além de ter conhecimento da finalidade da captação destes dados.

Como exemplo desta legislação internacional, pode-se citar o artigo 35, da Constituição Portuguesa que, apesar de não cunhar o termo "direito à autodeterminação informativa", descreve o que se entende por este conceito. A Alemanha, em decisão de seu Tribunal Constitucional, foi mais incisiva no reconhecimento deste direito quando determinou sua existência como decorrência direta dos princípios da dignidade da pessoa humana e do livre desenvolvimento da personalidade.Determinou, ainda, que o direito à autodeterminação informativa é de natureza material e oponível contra o Estado. Para Konrad Hesse (1998, p. 329), compreende a faculdade de o particular determinar a revelação e o emprego de seus dados pessoais. Em consonância com a tendência de seus Estados-membros, a União Europeia também reconheceu este direito na Carta dos Direitos Fundamentais da União Europeia, em 2000 (NAVARRO, 2008).

Diante do exposto, percebe-se que o direito à privacidade, apesar das dificuldades em sua conceituação, deve ser preservado de forma a proteger o indivíduo de eventuais abusos de entes públicos ou privados. No próximo tópico, portanto, iniciar-se-á o estudo da colisão entre o direito à privacidade e o princípio da publicidade da Administração Pública, tratando inicialmente da transparência administrativa, publicidade e do direito de acesso à informação, de forma a determinar qual o limite da sobreposição do interesse público sobre o direito à privacidade individual.

\section{TRANSPARÊNCIA, PUBLICIDADE E DIREITO FUNDAMENTAL DE ACESSO À INFORMAÇÃO}

Bobbio (1997, p. 84) define democracia como "o governo do poder público em público". O autor faz o trocadilho com duas acepções de "público", uma oposta ao conceito de "privado", como em interesse público e interesse privado; e a outra oposta ao que é secreto. Dessa forma, ele traça o caráter público como regra do governo democrático, onde o segredo somente ocorreria em regime de exceção e, ainda assim, deveria cessar no momento em que cessasse o risco que o motivou.

As novas tecnologias da informação possibilitam uma aproximação entre governantes e governados até então desconhecida. Bobbio (1997, p. 88) considera que o poder "é tanto mais visível quanto mais próximo está". Sendo assim, a visibilidade dos atos estatais não depende apenas de sua publicidade, mas também da proximidade entre cidadão e Estado. Além disso, a transparência e a publicização dos atos administrativos possibilita um eficiente controle destes por parte da sociedade, em contraposição ao segredo, que constitui uma forma de evitar o julgamento e preservar o lugar do poder constituído.

No Brasil, esses princípios são assegurados pela Constituição Federal, primeiro em forma de direito fundamental, assegurado pelo artigo $5^{\circ}$, inciso XXXIII, do qual se lê: "todos têm direito a receber dos órgãos públicos informações de seu interesse particular, ou de interesse coletivo ou geral, que serão prestadas no prazo da lei, sob pena de responsabilidade, ressalvadas aquelas cujo sigilo seja imprescindível à segurança da sociedade e do Estado". Sendo assim, protege-se o direito de acesso à informação, que possibilita o controle supracitado, o qual é imprescindível para a realização da democracia e do Estado Social, entendido por Bobbio (1990, 
p. 74) como "não só no sentido de Estado que permeou a sociedade mas também no sentido de Estado permeado pela sociedade".

Os referidos princípios são tratados não só como direito fundamental do cidadão, mas também como dever do Estado. A Constituição Federal obriga o Estado a cumprir com cinco princípios da Administração Pública, quais sejam, legalidade, impessoalidade, moralidade, publicidade e eficiência. A publicidade, listada dentre estes princípios, obriga o Estado a realizar todos os seus atos de forma pública, aberta e visível a todos os cidadãos, ou seja, transparente. Trata-se de transformar a Administração em uma "casa de vidro", conferindo visibilidade externa aos processos decisórios do poder público (ARENA, 1997, p. 363-364).

A Constituição especifica, ainda, no parágrafo $3^{\circ}$, inciso II, do artigo 37 que: “A lei disciplinará as formas de participação do usuário na administração pública direta e indireta, regulando especialmente: II. o acesso dos usuários a registros administrativos e a informações sobre atos de governo, observado o disposto no art. $5^{\circ}, \mathrm{X}$ [direito à privacidade] e XXXIII".

Reiterando o texto normativo constitucional, a Lei Complementar $n^{\circ} 101$, de 04 de maio de 2000, apelidada de Lei de Responsabilidade Fiscal, prevê uma "ação planejada e transparente" pelo Estado e dedica um capítulo de seu texto para determinações práticas acerca da transparência, controle e fiscalização de seu cumprimento. Em seu artigo 48, caput e incisos, prescreve ações que a Administração Pública deve adotar a fím de garantir acesso às informações de interesse público. No caput do referido artigo há menção, inclusive, aos meios eletrônicos de comunicação, conforme se lê:

São instrumentos de transparência da gestão fiscal, aos quais será dada ampla divulgação, inclusive em meios eletrônicos de acesso público: os planos, orçamentos e leis de diretrizes orçamentárias; as prestações de contas e o respectivo parecer prévio; o Relatório Resumido da Execução Orçamentária e o Relatório de Gestão Fiscal; e as versões simplificadas desses documentos. (BRASIL, 2000)

Apesar de prever publicidade e transparência, o dispositivo constitucional é genérico e abstrato, uma vez que não traça instruções de aplicação destes deveres, e a Lei de Responsabilidade Fiscal, apesar de estabelecer tais instruções, é aplicável tão somente às leis, atos orçamentários e afins. Com a finalidade de abranger a totalidade dos atos administrativos, nos três Poderes (Executivo, Legislativo e Judiciário) e em todas as esferas de poder (município, Estados-membros e União), portanto, elaborou-se a Lei $n^{\circ}$ 12.527, de 18 de novembro de 2011, que regula o acesso à informação e se destaca como legislação inovadora, ao regulamentar obrigações e procedimentos para a obtenção de informações públicas em geral, o que não havia sido feito até então.

Uma das inovações operadas pela Lei de Acesso à Informação (LAI) é a responsabilização de instituições públicas, empresas e servidores públicos no caso de recusa de fornecimento de informações, garantindo aaccountability. Além disso, são passíveis de responsabilização ainda aqueles que deliberadamente retardarem o fornecimento de informações ou intencionalmente deixarem de fazê-lo de forma correta, completa ou precisa. Essas previsões evidenciam o objetivo firme e inclusivo adotado pela LAI.

Dentre as diretrizes estabelecidas pela Lei de Acesso à Informação está a "utilização de meios de comunicação viabilizados pela tecnologia da informação". A adoção dos meios de tecnologia da informação permite a formação de "uma espécie de aprofundamento e de generalização [...], de uma diversidade livre em espaços abertos de comunicação e de cooperação", ocasionando, consequentemente, a transposição da concretude das instituições governamentais atuais em versões virtuais destas compondo, desta forma, o que se denomina ciberdemocracia (LÉVY, 2003, p. 31). 
Considera-se que as redes informacionais não são responsáveis pela criação de um novo formato de democracia, mas que instituem um espaço que possibilita o intercâmbio e o fluxo de informações, com amplo acesso à comunicação e dados e que permitem envolvimento e formação de opinião pública diferenciada (FEITOSA, FREIRE, 2011).

O cumprimento desta diretriz garante a eficácia dos pressupostos básicos da democracia, garantindo a liberdade individual, a supremacia do interesse público e o respeito à vontade geral. Nesse sentido, há uma quebra de paradigma que vinha se operando ao longo das produções legislativas, culminando na aprovação da Lei de Acesso à Informação, onde a cultura do segredo deu lugar à cultura da transparência, que possui a tendência de se consolidar através do uso das novas tecnologias. Ao utilizar as novas tecnologias da informação para efetivação destes pressupostos, permite-se que a democracia aproveite o melhor das consequências do ciberespaço, proporcionando o surgimento de uma nova forma de fazer política, que se estende, dentre outros, para o Judiciário.

A utilização das novas tecnologias da informação como forma de garantir a publicidade dos atos administrativos configura uma solução eficaz para o problema da transparência num país de dimensões continentais, como o Brasil, onde a população se encontra espalhada em território extenso e sofre de desnível econômico, social e educacional sem proporções. Sendo assim, a publicização das decisões estatais online se apresenta como uma possível solução, já que viabiliza a divulgação de dados de maneira uniforme, alcançando toda a extensão territorial do país e facilita o acesso à informação por toda a sociedade. Essa uniformização da disponibilização de dados e documentos configura política pública desenhada de modo a superar a distância existente entre a larga parcela da população sem acesso materiais e intelectuais e as oportunidades criadas pela era da informatização, que proporciona a participação cidadã e consolida direitos fundamentais, tais como o acesso à informação para a construção de uma cidadania ativa no Brasil.

Aqui desponta claramente a ligação entre os desenvolvimentos institucionais e as inovações tecnológicas: justamente estes tornam possível propor uma generalização do direito de acesso, no momento em que eliminam os obstáculos de caráter 'físico' que, no passado, tornavam impossíveis ou extremamente difíceis os acessos à distância, múltiplos, distribuídos em um arco de tempo mais amplo que aquele do horário ordinário dos escritórios, e assim por diante. (RODOTÀ, 2008, p. 69)

O e-government ou governo eletrônico, como se passou a chamar essa nova faceta do fazer político, resguarda o direito de acesso à informação e a transparência administrativa, na medida em que informa os cidadãos acerca dos investimentos e decisões realizados pelo Estado, além de garantir acesso a documentos, reclamações e solicitações. Dessa forma, o $e$ governmentse apresenta como uma ferramenta eficaz de proteção aos princípios democráticos, porquanto assegura a visibilidade e publicidade das decisões governamentais(MEZZAROBA, 2008).As características atribuídas à ciberdemocracia, dentre elas, o já mencionado direito de acesso à informação, oportunizam ainda, aaccountability, entendido aqui como a possibilidade de fiscalização dos atos administrativos pela sociedade e, mais ainda, a responsabilização do Estado por eventual má conduta burocrática (CAMPOS, 1990).

Há correntes, no entanto, que alertam para os riscos inerentes à Sociedade Informacional, uma vez que este fluxo intenso de informações pode ser manipulado pela parcela social de maior poder, seja esta parcela os governantes ou particulares influentes e de alto poder econômico. Nesse sentido, Marcuse (1999, p. 73) evidencia em seu discurso a já mencionada "face de Janos" compartilhada pelo ideal democrático e pela larga utilização dos avanços tecnológicos: 
A tecnologia, como modo de produção, como a totalidade dos instrumentos, dispositivos ou invenções que caracterizam a era da máquina, é assim, ao mesmo tempo, uma forma de organizar e perpetuar (ou modificar) as relações sociais, uma manifestação do pensamento e dos padrões de comportamento dominantes, um instrumento de controle e dominação.

Diante do exposto, percebe-se a importância da transparência e publicidade administrativas para a garantia dos princípios democráticos. Assim, em contraposição à primeira seção deste ensaio, passar-se-á à análise da colisão entre o princípio da publicidade e o direito à privacidade.

\section{ANÁLISE HERMENÊUTICA DA COLISÃO ENTRE O PRINCÍPIO DA PUBLICIDADE E O DIREITO À PRIVACIDADE SOB O ENFOQUE DA TEORIA DOS DIREITOS FUNDAMENTAIS DE ALEXY}

No contexto exposto ao longo deste ensaio, pode-se visualizar clara colisão entre normas de direitos fundamentais, mais especificamente, entre princípios, adotando-se, aqui, como marco teórico, a Teoria dos Direitos Fundamentais elaborada por Alexy (2008).

Tanto o direito à privacidade quanto o direito de acesso à informação são caracterizados como princípios, segundo a teoria de Alexy (2008, p. 90), uma vez que ambos são caracterizados por poderem ser "satisfeitos em graus variados e pelo fato de que a medida devida de sua satisfação não depende somente das possibilidades fáticas, mas também das possibilidades jurídicas". Assim, percebe-se que a colisão entre estes princípios deve ser estudada caso a caso com a finalidade de determinar precisamente qual o contexto fático e jurídico em que ela se insere, para que então se possa analisar a medida em que cada um será satisfeito.

A fim de solucionar uma colisão aparente entre princípios busca-se sopesá-los para determinar qual dos princípios possui precedência sobre o outro. A esse sopesamento, Alexy (2008) dá o nome de "lei de colisão". Para efetuá-lo, deve-se contrapor as normas contrárias, de forma que o princípio prevalente restrinja as possibilidades jurídicas do outro princípio, com base nas circunstâncias do caso concreto (ALEXY, 2008).

Levantam-se algumas críticas à aplicação da "lei de colisão" pelos Tribunais Constitucionais, pois acredita-se haver ausência de critérios objetivos para sua aplicação, o que possibilitaria um resultado encontrado através da livre criação jurídica do julgador. Ao analisar estudos norte-americanos e germânicos acerca da colisão entre princípios, Novais (2010) conclui que não se encontram termos de comparação entre princípios fundamentalmente diferentes e exemplifica, citando o direito à privacidade e a saúde pública, princípios análogos aos que se estudam no presente ensaio.

Assim, a fundamentação da decisão dos casos difíceis na ponderação de bens acabaria por redundar num raciocínio circular que evidenciaria o caráter de fórmula vazia do método. [...] Por sua vez, na ausência de regra constitucional de preferencia ou de uma ordenação natural resultante da ordem jurídica, não há quaisquer critérios ou parâmetros jurídicos que permitam ao aplicador chegar a uma decisão racional e controlável da preferência a estabelecer no caso concreto. (grifo no original. NOVAIS, 2010, p. 682-683)

Acredita-se ainda que ao sopesar direitos fundamentais de forma sistemática "produzirse-ia uma equalização redutora da especificidade jurídica de cada direito fundamental e degradarse-iam os direitos fundamentais a meros interesses, referências ou "pontos de vista de ponderação' que deveriam ser contrapostos a outros interesses ou pontos de vista" (NOVAIS, 2010, p. 681). Sendo assim, sem a existência de critérios objetivamente verificáveis o 
ordenamento jurídico termina por ficar vulnerável à livre criação subjetiva do julgador, passível da interferência ideológica individual deste, que possui como consequência a imprevisibilidade do ordenamento, a insegurança jurídica e, por fim, o risco de violação à separação dos Poderes, uma vez que o juiz constitucional passa a regular lacunas legislativas e a decidir acerca de políticas públicas do Executivo.

A colisão se torna mais palpável a partir do momento em que se pode visualizá-la na prática. Para tanto, cita-se como caso paradigmático para ilustrar a colisão a divulgação nominal da remuneração de servidores públicos.

Quanto à divulgação nominal da remuneração de servidores públicos alega-se que divulgar o nome individualizado do servidor, especificando o valor de sua renda mensal é violação do direito à privacidade, não só pelo caráter íntimo do salário de cada indivíduo, mas também devido à realidade específica brasileira, onde se pode colocar em risco a integridade física do servidor e, eventualmente, de sua família ao divulgar sua remuneração.

É pacífica a noção de que os limites da privacidade do servidor público ficam borrados frente à sua função governamental e à responsabilidade de prestação de contas perante a população. No entanto, o interesse público se estende somente à utilização do orçamento estatal, bastando, dessa forma, publicizar, tão somente o valor da remuneração investido pelo Estado em recursos humanos por cargo, conferindo, assim, maior discrição à vida privada do servidor individual.

Sabe-se, no entanto, que o Supremo Tribunal Federal (STF) adota o posicionamento pela prevalência do interesse público e da transparência. Nesse sentido, propõe-se a análise da decisão da Suspensão de Segurança (SS) no 3902/SP, julgada pelo STF em 2011, em que servidores públicos do Município de São Paulo requerem a retirada da especificação nominal de sua remuneração do sítio eletrônico público "De Olho nas Contas" (equivalente ao Portal da Transparência).

Lê-se do voto do Ministro Ayres Britto (2011, online):

14. De saída, percebe-se claramente que se está diante de um conflito aparente de normas constitucionais cuja solução passa pela exata compreensão dos valores consagrados nos princípios aplicados ao caso, tantas vezes referidos ao longo desta decisão. Se, por um lado, temos o princípio da moralidade e o princípio da publicidade (sendo ambos dedutíveis do princípio republicano - res publica); de outra banda, temos o risco de violação à intimidade, à vida privada, ao sigilo de dados e ao direito à segurança, princípios que desautorizariam a divulgação tal como pretendida pela Administração municipal.

15. Como desde logo se evidencia, a controvérsia é tão instigante quanto complexa, merecendo maior aprofundamento quando do julgamento de mérito da demanda.

16. Por ora, vocalizo a idéia de que o princípio da publicidade administrativa (caput do art. 37) significa o dever estatal de divulgação dos atos públicos. Dever eminentemente republicano, porque a gestão da "coisa pública" (República é isso) é de vir a lume com o máximo de transparência. Tirante, claro, as exceções também constitucionalmente abertas, que são "aquelas cujo sigilo seja imprescindível à segurança da sociedade e do Estado" (inciso XXXIII do art. $5^{\circ}$ ). Logo, respeitadas que sejam as exceções constitucionalmente estampadas, "todos têm direito a receber dos órgãos públicos informações de seu interesse particular ou de interesse coletivo ou geral, que serão prestadas no prazo da lei, sob pena de responsabilidade (...)", conforme a $1^{\text {a }}$ parte redacional do mesmo art. $5^{\circ}$. Com o que os indivíduos melhor se defendem das investidas eventualmente ilícitas do Estado, enquanto os cidadãos podem fazer o concreto uso do direito que a nossa Constituição lhes assegura pelo $\S 2^{\circ}$ do seu art. 72 $[\ldots]$. 
17. De outra vertente, a situação dos servidores públicos cai sob a regência da $1^{\mathrm{a}}$ parte do inciso XXXIII do art. $5^{\circ}$ da Constituição. Sua remuneração bruta, cargos e funções por eles titularizados, órgãos de sua formal lotação, tudo é constitutivo de informação de interesse coletivo ou geral. Expondo-se, portanto, a divulgação oficial. Sem que sua intimidade, vida privada e segurança pessoal e familiar se encaixem nas exceções de que trata a parte derradeira do mesmo dispositivo constitucional (inciso XXXIII do art. $5^{\circ}$ ), pois o fato é que não estão em jogo nem a segurança do Estado nem a segurança do conjunto da sociedade.

18. Em suma, esta encarecida prevalência do princípio da publicidade administrativa outra coisa não é senão um dos mais altaneiros modos de concretizar a república enquanto forma de governo. Se, por um lado, há um necessário modo republicano de administrar o Estado brasileiro, de outra parte é a cidadania mesma que tem o direito de ver o seu Estado republicanamente administrado. O "como" se administra a coisa pública a preponderar sobre o "quem" administra - falaria Norberto Bobbio -, e o fato é que esse objetivo modo público de servir a máquina estatal é elemento conceitual da nossa República. O olho e a pálpebra da nossa fisionomia constitucional republicana.

De leitura do voto, pode-se verificar a ausência dos critérios objetivamente verificáveis citados por Novais (2010), uma vez que o Ministro procede tão somente com a definição do princípio da publicidade e transparência administrativas e julga pela precedência deste, sem desprender qualquer tempo para a análise do princípio da publicidade, contra o qual o anterior é sopesado.

O Ministro Relator desta decisão se utiliza de apenas cinco parágrafos, em menos de três laudas, para discorrer sobre a colisão entre os princípios aqui debatidos. Ele reputa ao caso apenas um "[...] aparente estado de colisão. Aparente conflito, e não mais que isto". Mitiga-se o direito à privacidade do servidor público afirmando-se que "é o preço que se paga pela opção por uma carreira pública no seio de um Estado republicano". Neste sentido, não se opera a realização de cada princípio na maior medida do possível, como determinado pela lei da colisão de Alexy (2008). Ao contrário, tratam-se os princípios como regras, onde um (o princípio da publicidade administrativa) afasta o outro (direito à privacidade), que não se encaixa em suas exceções constitucionalmente previstas.

Os demais ministros seguem o relator em seus votos, não se aprofundando na discussão. Nenhum deles sequer menciona a colisão de princípios, nem o direito à autodeterminação informativa. Vale mencionar o voto do Ministro Luiz Fux, que alega que o argumento da ameaça à proteção da pessoa do servidor ou de sua família é falacioso. Explica que a riqueza do servidor estaria expressa em seu estilo de vida, que seria condizente com o valor de sua remuneração, não importando se este valor estaria ou não publicizado nos Portais da Transparência. O Ministro Marco Aurélio também segue o relator em sua postura, afastando definitivamente o direito individual em favor do interesse público, sem buscar realizar cada princípio em sua máxima medida.

A decisão da Suspensão de Segurança 3.902 foi reiterada pelo STF este ano (2015), em julgamento do Recurso Extraordinário com Agravo nº 652.777, que teve como relator o Ministro Teori Zavascki. Em seu relatório, o ministro citou a decisão da SS 3.902, no entanto não entrou no mérito da colisão de princípios.

Diante do estudo efetuado acerca do princípio da publicidade, consagrado como princípio constitucional da Administração Pública e o direito fundamental à privacidade e da aplicação de seu sopesamento por meio da "lei da colisão" de Alexy (2008) pelo STF, elaborouse uma possível solução para as críticas esboçadas, a ser tratada na próxima seção. 


\section{DIREITO À AUTODETERMINAÇÃO INFORMATIVA COMO SOLUÇÃO À COLISÃO ENTRE O PRINCÍPIO DA PUBLICIDADE E O DIREITO À PRIVACIDADE}

O exemplo analisado neste ensaio, da Suspensão de Segurança $\mathrm{n}^{\circ} 3.902$, evidencia as críticas postas por Novais (2010) e aqui destacadas. Independente da opinião pessoal do leitor ou dos autores do ensaio a respeito desta colisão específica ou do caso em tela, não se pode negar que o ordenamento jurídico brasileiro possui falhas na aplicação da "lei de colisão" como pensada por Alexy (2008) e, assim, propõe-se um impasse genérico acerca da colisão de princípios, ainda sem resposta.

No entanto, para o caso concreto apresentado e analisado, sugere-se uma solução, a qual se acredita respeitar em determinada medida tanto o princípio da publicidade quanto a privacidade dos servidores públicos.Para melhor visualização, e antes de apresentar a solução possível para a colisão proposta, se decidiu expor de maneira sistemática o estudo elaborado neste ensaio. Dessa forma, pode-se resumir a análisedestes princípios da seguinte maneira:

Tabela 1. Quadro resumo dos argumentos expostos

\begin{tabular}{|l|l|}
\hline \multicolumn{1}{|c|}{$\begin{array}{c}\text { A proteção do princípio da publicidade é } \\
\text { necessária para garantir: }\end{array}$} & \multicolumn{1}{|c|}{$\begin{array}{c}\text { A proteção do direito à privacidade é } \\
\text { necessária para garantir: }\end{array}$} \\
\hline Democracia & Democracia \\
\hline Supremacia do interesse público & Bem estar individual \\
\hline Acesso à informação & Segurança individual \\
\hline Accountability & Liberdade individual \\
\hline
\end{tabular}

Do exposto, percebe-se que o problema pode ser resumido, basicamente, pelo embate entre direitos individuais versus direitos coletivos. Sendo assim, busca-se uma solução onde se poderia proteger o máximo possível a individualidade dos servidores público, levando-se em consideração o esmaecimento inevitável dos limites de seu direito à privacidade e, ao mesmo tempo, cumprir com o dever do Estado de transparência e direito coletivo à informação.

Neste contexto, a divulgação da remuneração individualizada dos servidores poderia ser feita de forma a omitir seu nome, podendo constar nos Portais da Transparência a remuneração individualizada por cargo e matrícula do servidor, ou ainda, com as iniciais de cada um, como se faz com os processos na Justiça do Trabalho. Dessa forma, se respeitaria o interesse público e o acesso às informações referentes ao orçamento estatal, pois se saberia quanto o governo despende em recursos humanos e, especificamente, em cada cargo. Além de permitir visualizar eventuais diferenças entre a remuneração de indivíduos que possuem o mesmo cargo, possibilitando o exercício da accountability.

Esta solução permite, ainda, a proteção da privacidade e da intimidade do servidor público que, apesar de ter sua remuneração divulgada nos Portais da Transparência, se protege de eventuais violações à sua liberdade e segurança. Como lembra Gregorio Arena, há alguns interesses públicos e privados que merecem proteção:

Ningún sistema administrativo puede ser totalmente transparente, ni totalmente opaco: como em todos los demás sectores, también em la decisión sobre la amplitud de la transparência entran em juego interesses, públicos y privados, que deben ser ponderados entre sí a fin de encontrar El punto de equilibrio entre exigências contra puestas (1997, p. 365). 
Deve-se, por fim, facultar ao servidor a opção de publicar seu nome, caso sinta que seu direito à privacidade não seria violado por este ato. Esta faculdade garantiria, por sua vez, a proteção a um novo direito à autodeterminação informativa, que passa a ganhar contornos no ordenamento jurídico nacional e internacional, e para Canotilho (2003, p. 515), "se traduz, fundamentalmente, na faculdade de o particular determinar e controlar a utilização de seus dados pessoais".

Este direito à autodeterminação informativa é material e oponível em face do Estado. Ele se limita pela lei e por manifesto interesse público, devendo atender ao princípio da proporcionalidade, como se fez com o caso analisado (NAVARRO, 2012).

Dessarte, acredita-se que as soluções propostas respeitam na maior medida possível os princípios em colisão, limitando-os somente onde necessário. Apresenta-se, ainda, um sopesamento responsável, racional, onde se consideram todas as variáveis das normas colidentes e se garante tanto a realização do interesse público quanto a proteção da individualidade.

\section{CONCLUSÃO}

A realidade líquida, descrita por Bauman (2011), que se relaciona com a sociedade da informação, realiza profundas modificações nas relações sociais, alterando, inclusive, a forma como o indivíduo e o Estado se relacionam. Esta sociedade informacional apresenta contradições próprias às suas características e às mudanças que opera nas instituições sociais.

As contradições da era da informação afetam diretamente a forma como a privacidade e a intimidade são vistas e os limites sobre o controle que as instituições públicas e privadas podem exercer sobre os dados pessoais divulgados na rede mundial de computadores.

Neste contexto, o presente ensaio apresenta a colisão entre o princípio constitucional da Administração Pública da publicidade e o direito fundamental à privacidade, ambos resguardados pela Constituição Federal de 1988, utilizando como marco teórico a Teoria dos Direitos Fundamentais de Alexy (2008).

Na primeira seção, estuda-se o conceito e as características do direito à privacidade e as mudanças que este conceito sofreu no curso histórico e com as transformações sociais operadas pela larga utilização das novas tecnologias da informação. Conclui-se, assim, que apesar das dificuldades em sua conceituação, este deve ser preservado de forma a proteger o bem estar, a segurança e a liberdade individual de eventuais abusos de entes públicos ou privados.

No tópico seguinte, analisa-se o princípio constitucional da Administração Pública da publicidade e seus desdobramentos, como a transparência e o direito de acesso à informação, no contexto da ciberdemocracia e do e-government. Trata-se da importância de sua proteção para a preservação da democracia, da supremacia do interesse público e da accountability. Conclui-se, daí, que a proteção deste princípio é fundamental para a garantia do Estado Democrático de Direito.

Passa-se à análise, na terceira seção, da colisão entre estes direitos sob o enfoque da Teoria dos Direitos Fundamentais de Alexy (2008), por meio da apresentação da Suspensão de Segurança $n^{\circ}$ 3902, julgada pelo STF, na qual se pede a retirada da divulgação nominal da remuneração dos servidores públicos do município de São Paulo. Critica-se a decisão analisada, pois os Ministros julgam uma colisão entre princípios como se entre regras fosse, afastando definitivamente o direito individual à privacidade em favor do interesse público expresso pelo princípio da publicidade administrativa. Percebe-se que não há sopesamento de princípios e que estes não são realizados na máxima medida do possível, conforme prevê Alexy (2008). O reconhecimento do direito à autodeterminação informativa, apresentado no presente trabalho como uma nova faceta do direito à privacidade e possível solução para este sopersamento, sequer é mencionado. 
Nesse sentido, conclui-se que o Supremo Tribunal Federal não analisou adequadamente os direitos e interesses em colisão, ignorando a questão da privacidade dos servidores públicos, que há de ser levada a sério. Percebe-se, assim, que a decisão foi tomada com base tão somente na livre escolha do julgador, o que ocasiona insegurança jurídica, imprevisibilidade das decisões e riscos para o princípio da separação dos Poderes.

Recapitulando todo o estudo feito ao longo do ensaio, conclui-se o trabalho com a sugestão de uma possível solução para a problemática em tela: a divulgação das remunerações individualizadas por servidor, respeitando o princípio da publicidade e transparência, mas sem o nome deste, que pode ser substituído pela matrícula ou pelas iniciais, conforme se faz na Justiça do Trabalho ou nos processos que correm em segredo de justiça, conferindo proteção à privacidade do indivíduo.

Sugere-se, por fim, a reconhecimento do direito à autodeterminação informativa, neste caso, para o servidor decidir se quer que seu nome seja publicizado. Acredita-se, assim, que as soluções propostas respeitam na maior medida possível os princípios em colisão, limitando-os somente onde necessário, como fruto de um sopesamento responsável, racional, onde se consideram todas as variáveis das normas colidentes e se garante tanto a realização do interesse público quanto a proteção da individualidade.

\section{REFERÊNCIAS}

ALEXY, Robert. Teoria dos Direitos Fundamentais. 3. Ed.São Paulo: Malheiros, 2008.

ARENA, Gregorio. La transparencia administrativa. In: Documentación Administrativa. Madri, n. 248-249, maio/dezembro de 1997, p. 361-405.

BAUMAN, Zygmunt. 44 cartas do mundo líquido moderno. Rio de Janeiro: Zahar, 2011.

BOBBIO, Norberto. Estado, governo, sociedade - para uma teoria geral da política. 8a ed. São Paulo: Paz e Terra, 1990.

Terra, 1997.

. O Futuro da Democracia: Uma defesa das regras do jogo. 6. ed. São Paulo: Paz e

BRASIL. Constituição (1988). Brasília, DF, 05 out. 1988. Disponível em: <http://www.planalto.gov.br/ccivil_03/constituicao/constituicao.htm>. Acesso em: 01 nov. 2014.

. Lei Complementar n ${ }^{\circ} 101$, de 04 de janeiro de 2000. Estabelece normas de finanças públicas voltadas para a responsabilidade na gestão fiscal e dá outras providências.. Dou. Brasília, $\quad 05 \quad$ jan. $2000 . \quad$ Disponível <http://www.planalto.gov.br/ccivil_03/leis/lcp/lcp101.htm>. Acesso em: 07 jun. 2015.

Lei $\mathrm{N}^{\mathrm{o}}$ 12.527, de 18 de novembro de 2011. Regula o acesso a informações previsto no inciso XXXIII do art. $5^{\circ}$, no inciso II do $\S 3^{\circ}$ do art. 37 e no $\S 2^{\circ}$ do art. 216 da Constituição Federal; altera a Lei ${ }^{\circ}$ 8.112, de 11 de dezembro de 1990; revoga a Lei $\mathrm{n}^{\circ} 11.111$, de 5 de maio de 2005, e dispositivos da Lei $\mathrm{n}^{\circ}$ 8.159, de 8 de janeiro de 1991; e dá outras providências. Disponível em <http://www.planalto.gov.br/ccivil_03/_Ato2011-2014/2011/Lei/L12527.htm>. Acesso em: 30 mai 2012. 
Supremo Tribunal Federal. Agravo Regimental. [...]. Suspensão de Segurança 3902AgR-segundo/SP. Tribunal Pleno. Agravantes: Sindicato dos Especialistas de Educação do Ensino Público do Município de São Paulo - SINESP e Associação dos Engenheiros, Arquitetos e Agrônomos Municipais de São Paulo e outro (a/s). Agravado: Município de São Paulo. Relator(a): Min. Ayres Britto. Brasília, 09 de junho de 2011. Disponível em: < http://www.stf.jus.br/portal/jurisprudencia/listarJurisprudencia.asp?s1=\%28ss+3902\%29\&bas e=baseAcordaos $>$. Acesso em: 27 mai 2015.

CAMPOS, Anna Maria. Accountability: quando poderemos traduzi-la para o português? Revista de Administração Pública, Rio de Janeiro, fev./abr. 1990. Disponível em: <http://admsp20061.wikispaces.com/file/view/Accountability-+Quando+poderemos+traduzila+par+o+portugu\%C3\%AAs+-+Anna+Maria+Campos.pdf> Acesso em: 03 jun. 2015

CANOTILHO, José Joaquim Gomes. Direito Constitucional e Teoria da Constituição. 7. ed. Coimbra: Almedina, 2003

CELLA, José Renato Graziero; ROSA, Luana Aparecida dos Santos. Controle Social e Necessidade de Proteção de Dados Pessoais. Revista Democracia Digital e Governo Eletrônico, Florianópolis, v. 9, n. 1, p.158-171, jul. 2013. Disponível em: <http://buscalegis.ufsc.br/revistas/index.php/observatoriodoegov/article/view/34284/33163>. Acesso em: 05 jun. 2015.

FEITOSA, Gustavo Raposo Pereira; FREIRE, Geovana Maria Cartaxo de Arruda. Governo Eletrônico e Ciberdemocracia na Gestão Pública Brasileira. In: Joyceane Bezerra de Menezes; Renata Albuquerque Lima. (Org.). Justiça Social e Democracia. Florianópolis: Conceito Editorial, 2011, p. 179-202.

GOYARD-FABRE, Simone. O que é democracia?: A genealogia filosófica de uma grande aventura humana. São Paulo: Martins Fortes, 2003.

HESSE, Konrad. Elementos de direito constitucional da República Federal da Alemanha. Porto Alegre: Sérgio Antônio Fabris Editor, 1998.

LESSIG, Lawrence. Code and other laws of Cyberspace. 2. ed. New York: Basic Books, 2006. Disponível em: <http://codev2.cc/download+remix/Lessig-Codev2.pdf>. Acesso em: 09 maio 2015.

LÉVY, Pierre. Cibercultura. São Paulo: 34, 1999. . Ciberdemocracia. Lisboa: Piaget, 2003.

MARCUSE, Herbert. Tecnologia, Guerra e Facismo. São Paulo: Fundação Editora da Unesp, 1999. Editado por Douglas Kellner.

MEZZAROBA, Orides. A representatividade política na era da informação e o espaço reservado ao povo. In: ROVER, Aires José (Ed.). Inclusão Digital e Governo Eletrônico. Zaragoza: Prensas Universitarias de Zaragoza, 2008. Cap. 2. p. 39-52. 
NAVARRO, Ana Maria Neves de Paiva. O direito fundamental à autodeterminaçãoinformativa. In: XXI Congreso Nacional do CONPEDI. Direitos Fundamentais eDemocracia II. Florianópolis: FUNJAB, 2012. 2 p. 410-438. Disponível em:<http://www.publicadireito.com.br/artigos/?cod=86a2f353e1e6692c $>$. Acesso em: 20abr.2014.

NOVAIS, Jorge Reis. As Restrições aos Direitos Fundamentais não Expressamente Autorizadas pela Constituição. 2. ed. Coimbra: Coimbra, 2010.

ORGANIZAÇÃO DOS ESTADOS AMERICANOS. Comissão Interamericana de Direitos Humanos. Denúncia. San José, Costa Rica. Disponível em: <http://s.conjur.com.br/dl/denunciaap-470-cidh.pdf>. Acesso em: 30 out. 2014.

RODOTÀ, Stefano. A vida na sociedade da vigilância: A privacidade hoje. Rio de Janeiro: Renovar, 2008.

WARREN, Samuel D.; BRANDEIS, Louis D.The Right of Privacy.In:Harvard Law Review, Harvard, v. IV, n. 5, dec. 1890, p. 214.

SOLOVE, Daniel J.. Conceptualizing Privacy. California Law Review,San Diego, v. 90, n. 4, p.1087-1156, jul. 2002. Disponível em: <http://scholarship.law.berkeley.edu/cgi/viewcontent.cgi $?$ article=1408\&context=californialawrev iew>. Acessoem: 01 jun. 2015.

A Taxonomy of Privacy. University Of Pennsylvania Law Review, Pennsylvania, v. 154, n. 3, p.477-560, jan. 2006. Disponível em: <https://www.law.upenn.edu/journals/lawreview/articles/volume154/issue3/Solove154U.Pa.L.Re v.477(2006).pdf>. Acesso em: 01 jun. 2015. 